\title{
El poblamiento rural de la tierra de Loja a fines de la Edad Media
}

Miguel Jiménez Puertas

A fines de la Edad Media se producen importantes transformaciones a todos los niveles en el reino nazarí de Granada como consecuencia de la conquista castellana. El control y la ocupación del territorio por parte de los cristianos, máxime en las zonas donde la población musulmana desaparece o queda como un grupo muy minoritario, dieron lugar a trascendentales modificaciones en la organización social del espacio en función de los intereses derivados de la estructura social y de poder característica de la sociedad castellana, cualitativamente diferente de la nazarí. En esta línea de trabajo se sitúa el presente estudio que pretende analizar la evolución del poblamiento rural durante la época nazarí y las modificaciones que tienen lugar tras la conquista castellana en una zona concreta, la tierra de Loja, que se caracteriza por su situación fronteriza.

\section{EL POBLAMIENTO NAZARÍ}

La tierra de Loja constituía en época nazarí una división político-administrativa cuya delimitación territorial heredó el Concejo castellano organizado tras la conquista de I486, tal como queda claro cuando los repartidores disponen "señalar e alindar los terminos d'esta ciudad de Loxa ... por donde los moros los tenian en el tiempo que la çiudad era de moros"', por lo cual podemos saber de forma aproximada su extensión gracias a que conocemos esta delimitación realizada a raíz de la ocupación casteIlana (MALPICA, 198I, pp. 39-57). Todo el conjunto que englobaba este territorio estaba organizado en torno a la ciudad de Loja. Esta ciudad era un importante núcleo de población ${ }^{2}$ estructurado en tres sectores: la Alcazaba, situada en el peñón que domina el resto de la ciudad, con una función eminentemente militar; el barrio del Jaufín, situado al norte, que estaba amurallado; y el Arrabal, ubicado en la zona sur, también amurallado, y que en el momento de la llegada de los castellanos es el sector más destacado de la ciudad, dado que es probablemente el más pobladoª , el que cuenta con la más importante infraestructura comercial ${ }^{4}$ y donde se ubicó la Iglesia Mayor cristiana. La ciudad era además la sede del poder político-militar, el cual estaba personificado en el alcaide de Loja. Mención especial merece la gran importancia de la figura de "Alatar", que fue alcaide de Loja durante gran parte de la segunda mitad del siglo XV hasta su muerte en 1483 durante la batalla de Lucena, en la cual los castellanos capturaron a Boabdil.

\footnotetext{
IBARRIOS AGUILERA, M. (1988): Libro de los Repartimientos de Loja. Granada, f. XXVIII. En adelante citaremos esta edición abreviadamente como LRL.

2 En 1489 se habían repartido 456 lotes de casas, lo que puede dar idea del volumen demográfico de la ciudad (LRL, fols. I-29 v).

3 De los 456 lotes de casas repartidos en 1489, 4 I están en la Alcazaba, 19l en el Jaufín y 224 en el Arrabal (LRL, fols. I-29v).

4 El Concejo recibió en el Arrabal un mesón y veinte tiendas (LRL, fols. 4-18 v y I52 v).
} 
Su control sobre el resto de los castillos o fortalezas de la tierra de Loja explica que una crónica castellana se refiera a él como alcaide de Loja y señor de Zagra (BAEZA, I868, p. 23). Sin embargo este control no lo hace a título personal. No es realmente un "señor" tal como entendían los castellanos, sino que ejerce este poder como representante en esta zona del Estado, es decir, del sultán de Granada. Esta cuestión está perfectamente clara tal como se aprecia en un precioso y brevísimo documento de 1487 estudiado por A. Malpica Cuello, que además revela la relación fiscal entre los lugares del alfoz, en este caso Zagra, y su cabecera, ya que indica que, en época de paz, "el diesmo dauan en Loxa" (MALPICA, 1987).

En este contexto de un territorio fuertemente influenciado por el mundo urbano es en el que encontramos un poblamiento rural que es el resultado tanto de una herencia anterior como de las circunstancias nuevas que surgen en esta etapa, sobre todo en relación con el carácter fronterizo que adquiere este sector del reino de Granada a fines de la Edad Media. Combinando el análisis de las fuentes escritas, entre las que destaca el Libro de Repartimiento de Loja, y los resultados de la prospección arqueológica, hemos intentado determinar las alquerías existentes en época nazarí. En este sentido, tenemos que señalar que dado que las fuentes escritas, tanto árabes como castellanas, son muy parcas a la hora de informarnos sobre la red del poblamiento rural en época nazarí, nos hemos aproximado al conocimiento de ésta partiendo de la hipótesis de que las torres existentes en zonas de topografía llana y junto a espacios cultivados, sobre todo si éstos son de regadío, son fortificaciones vinculadas a alquerías, entendidas éstas como núcleos de población que tienen una cierta entidad demográfica y unos límites propios, aunque no habría que descartar que haya que vincularlas a otro tipo de poblamiento disperso como almunias o cortijos. Esta problemática no evita que podamos distinguir claramente a nivel espacial en el conjunto de la tierra de Loja dos sectores con características diferenciales: la Vega de Loja y el resto del territorio vinculado a esta ciudad. Tras el análisis de ambos territorios pasaremos posteriormente a estudiar individualmente las alquerías existentes.

\section{Análisis territorial del poblamiento rural nazarí}

La Vega de Loja constituye una llanura aluvial que se extiende en torno al río Genil en el tramo situado entre las desembocaduras de sus afluentes Cacín y Riofrío, en cuyos márgenes encontramos zonas alomadas arcillosas y, sobre todo, las sierras de Loja y del Hacho, que estrechan la Vega a la altura de la ciudad $y$, en consecuencia, esta zona se convierte en un obligado paso que pone en contacto la Depresión de Granada con las de Archidona y Antequera, todas ellas en el denominado surco intrabético, así como con el Valle del Guadalquivir siguiendo el curso del río Genil. Junto a estas circunstancias hay otras que han contribuido a que la ocupación humana haya sido muy importante desde tiempos prehistóricos, destacando fundamentalmente el hecho de que las sierras calizas del Hacho y de Loja son unos inmensos acuíferos kársticos que afloran precisamente en la Vega de Loja, en importantes manantiales como son los de Riofrío, Plines, Manzanil, Frontil, etc.

Constatada la importancia del poblamiento romano en la zona -yacimientos de la Esperanza (PELLICER, 1962, pp. 330-331) y Plines (GENER, 1992, especialmente pp. 127128), entre otros-, se evidencia la existencia de una continuidad en época tardorromana (necrópolis de Loja, propiedades de Artobás ${ }^{5}$ ) que se prolonga en la época altomedieval con un importante asentamiento de individuos árabes del ŷund de Damasco a mediados del siglo VIII en Turruš, al-Funtayn y Šikanb. Esta

\footnotetext{
5 Artobás era uno de los hijos del rey Witiza que había heredado parte del patrimonio de los monarcas visigodos. Sus propiedades en esta zona las conocemos por el testimonio transmitido por lbn al-Qutiyya relativo a las fincas de al-Funtayn y Turrus, topónimos que se vienen ubicando en la tierra de Loja, que fueron donadas a dos individuos árabes (VALLVÉ, 1986, pp. 200-202).
} 
continuidad es probablemente la causante de la preponderancia de una toponimia de origen latino (Riofrío, Plines, Torrox, Loja, Manzanil, Salar, Frontil, etc.). Esta evidencia toponímica, así como las noticias proporcionadas por las fuentes escritas y las cronología aportada por el estudio de la cerámica recogida en la prospección de los yacimientos arqueológicos, llevan a concluir que las alquerías existentes en época nazarí tienen su origen en etapas precedentes y no ha tenido lugar en esta época el surgimiento de nuevos núcleos de población.

El elemento más característico de este grupo de alquerías de la Vega de Loja (Plines, Salar, Tájara, Huétor, Agicampe y Frontil) es el hecho de que su economía está basada fundamentalmente en la agricultura de regadío, pero además hay que destacar que en los últimos tiempos nazaríes constituyen la única zona donde se mantuvo una explotación agrícola importante y permanente, tal como demuestra el hecho de que es en esta zona donde el Libro de Repartimiento de Loja recoge la existencia de infraestructuras vinculadas a la agricultura (sistemas de regadío en Riofrío, Plines, Loja, Manzanil, Salar, Tájara, Huétor, Agicampe y Frontil; molinos en Plines, Terciado, Manzanil, Tájara y Frontil). Esta circunstancia estuvo favorecida por ser el sector más alejado de la frontera $y$, sin duda, por la proximidad de la ciudad de Loja, fortaleza en torno a la cual giraba la defensa del territorio. Además tuvo lugar una fortificación de las alquerías existentes en esta zona, constatándose en todos los casos la presencia de torres de diferente complejidad, como respuesta a las amenazas derivadas de las incursiones militares castellanas que se hacen más frecuentes en el siglo XV.

Desconocemos prácticamente todo en relación a las características de estas alquerías, pero vamos a intentar definir algunos rasgos.

A nivel de topografía de las alquerías sólo tenemos una alusión a las casas del arrabal de Salar, nombre que recibiría por su situación en los alrededores de la fortaleza de este lugar. Ya en época morisca se menciona en Huétor una estructura urbanística compuesta por el fuer- te, un barrio alto y un barrio nuevo, surgido éste probablemente ya en el siglo XVI.

En todos los casos una torre, o una fortaleza más compleja como en el caso de Tájara, dominaría desde el punto de vista visual el conjunto de la alquería. El estudio realizado por A. Bazzana y P. Guichard sobre las torres de alquería de la Huerta de Valencia en el siglo XIII les permitió concluir provisionalmente que este tipo de fortificaciones surgen en íntima relación con el aumento de la presión militar cristiana, sin ninguna vinculación a poder señorial alguno; es más, probablemente, han sido construidas a iniciativa del poder estatal. Su función era, además de estar integradas en el conjunto del sistema defensivo de un territorio, proteger a la población de la alquería, en este sentido no constituyen un elemento aislado, siendo habitual la existencia de un espacio de refugio $y$, en algunos casos, una muralla que protegía al conjunto de las casas. A nivel de poblamiento estas alquerías fortificadas hacen girar en su órbita al resto de las alquerías y al poblamiento disperso (almunias o cortijos) existentes en su entorno (BAZZANA, GUICHARD, 1978, pp. 103-I05). Pensamos que en el caso de la tierra de Loja las características que acabamos de exponer tienen validez en gran parte. Así, respecto a la cronología del surgimiento de estas fortalezas podemos asegurar que la técnica de construcción de las torres de Agicampe y Salar, es decir la mampostería ripiada formando hiladas con sillares en los ángulos rectos, es propia de la época nazarí (ESLAVA, 1984, pp. 276-277), lo que relaciona la construcción de estas edificaciones con la amenaza castellana derivada del carácter fronterizo de la tierra de Loja. En relación al carácter estatal y no señorial de estas torres, hemos de señalar que tenemos la información relativa a la iniciativa de Muhammad III para construir torres en las proximidades de la Vega de Granada (LADERO, 1989, p. 27). Ahora bien, también es cierto que en las propiedades de la familia real nazarí en esta zona existían torres, los alcázares mencionados en algunas crónicas castellanas, que eran a la vez fortaleza y palacio. Respecto al carácter de refugio de estas fortificaciones es ejemplar el caso de Tájara, según recogen las crónicas cas- 
tellanas, tal como veremos posteriormente al analizar individualmente cada núcleo de poblamiento rural existente en la tierra de Loja. En relación al carácter de estas alquerías con torre como elementos que vertebran el poblamiento rural existente en su entorno, nuestros datos sobre alquerías no fortificadas o sobre poblamiento disperso son muy escasos y no permiten corroborar esta cuestión.

Normalmente un camino de primer orden pasaba por la alquería o sus inmediaciones. La red de caminos "reales" de la tierra de Loja es radial, ya que éstos enlazaban las principales ciudades del reino, lo que nos informa del papel que juegan a nivel comercial las urbes, que concentran esta actividad. Pero esta red caminera principal también pasa por las alquerías, conectando así la ciudad con los núcleos rurales de su tierra. Ello no tiene sólo sentido desde el punto de vista comercial, sino también fiscal, debido a que los impuestos en especie se entregaban en la ciudad de Loja, como hemos visto anteriormente en el caso de Zagra. En este sentido sabemos que las autoridades eran las que decidían donde se entregaban los impuestos, como se constata en el caso de Málaga: "los moros de la jurediçión de la çibdad de Málaga sean obligados de poner el pan del dicho diezmo donde el dicho recabdador lo quisyere syendo en la jurediçión" (LADERO, 1988, doc. 76 bis, p. 407). En este sentido los caminos son, a todos los efectos, las vías por donde circula el excedente.

Junto a la alquería, por debajo de las casas, se sitúan los espacios irrigados, que constituyen en esta zona el elemento básico de la economía. Los sistemas de irrigación están construidos tanto a partir de ríos como de manantiales, creándose presas, como la mencionada en el Libro de Repartimiento de Loja en Salar, a partir de las cuales del agua se conduce por medio de acequias, algunos de cuyos nombres conocemos: "açequia gorda del rio de Caçin que biene a Taxara" (LRL, fol. I 40 v), "açequia alta" en Huétor (LRL, fol. 138), "açequia primera de Manzanil" (LRL, fol. 160). Incluidos en esta red se sitúan los molinos. Sobre los productos cultivados en estas áreas tenemos pocas noticias, lo que contrasta fuertemente con el minucioso detalle con que se puede conocer a través del Libro de Repartimiento de Loja el espacio de huertas situadas alrededor de la ciudad de Loja. La existencia de molinos indica que los cereales debían ser uno de los cultivos más importantes, lo cual está apoyado por el testimonio referente a Tájara que alude a los "muchos panes que ay abía" (CARRILLO, 1946, pp. 97-98). Sólo en referencia a Salar tenemos noticias de la existencia de olivos en el regadío.

Los cultivos de secano se sitúan entre el regadío y el monte, teniendo en esta zona un papel secundario, salvo en el caso del campo de Huétor, una amplia Ilanura aluvial sólo regada en una pequeña parte. El Libro de Repartimiento de Loja recoge la cuantía y ubicación de las tierras de secano repartidos a raíz de la repoblación castellana, pero no siempre tenemos la certeza de que estos campos estuviesen anteriormente cultivados, máxime en los casos, como en Plines, donde el secano se reparte en los Retamales, topónimo que alude a esta especie arbustiva propia del monte mediterráneo. Fuera de las áreas de secano, el Libro de Repartimiento de Loja recoge la presencia del monte o la sierra, aunque no suele ofrecer más especificaciones, salvo en algunos casos. Así en Salar, las tierras de secano entregadas a Fernando del Pulgar limitaban unas con "las ençinas del Portichuelo" (LRL, fol. I30 v) y otras se sitúan "entre unos çerros espartosos, que va a dar a unas ençinas" (LRL, fol. I48); en Tájara unas tierras de secano concedidas a Antonio de Córdoba lindan con "un pinar que está delante del Algarvejo" (LRL, fol. I40 v).

El resto del territorio vinculado a la tierra de Loja, pero alejado de la próspera llanura aluvial, presenta un poblamiento más débil, debido tanto a su situación fronteriza como a su vocación ganadera. Este conjunto se caracteriza por su pertenencia al subbético, presentando a grandes rasgos desde el punto de vista geomorfológico tres tipos de paisaje. Por una parte nos encontramos con las sierras calizas (Sierras Gorda de Loja, de 
Gibalto, del Hacho, de las Chanzas, etc.), actualmente sin vegetación, sometidas a una constante erosión. Por otra parte se sitúa una franja de tierra de naturaleza yesífera (Trías de Ante-quera), de relieve intrincado, caracterizada a nivel hidrológico por su endorreismo, lo que origina una zona de escasos cultivos y donde ha permanecido en gran parte una vegetación natural de tipo mediterráneo, aunque ésta representa sólo una parte de los bosques de encinas y quejigos existentes a finales de la Edad Media en la zona de los Durmientes (actual Dehesa de los Montes), las Salinas y el Contarín. Por último, hay que aludir a la existencia de otra zona de lomas suaves, que se extendía sobre todo en el sector noroeste del término de Loja, en los actuales términos municipales de Algarinejo y Zagra, donde en la actualidad se ha desarrollado casi de modo exclusivo el cultivo del olivar, pero que a finales de la Edad Media sería una zona también ocupada de modo abrumador por el bosque mediterráneo, salvo en las tierras próximas a las fortificaciones, donde existían campos cultivados.

El poblamiento existente en esta zona estuvo muy influenciado por el carácter fronterizo. En este sentido al amparo de los castillos de Cesna ${ }^{6}$ y Zagra debió desarrollarse un población más o menos importante, ya que ambos lugares son mencionados en las fuentes escritas castellanas como villas y en concreto Zagra aparece citada como "fortaleza enemiga de población pequeña" (MALPICA, 1987, p. 969). En torno a ambas fortalezas se repartieron tierras tras la conquista castellana ${ }^{7}$. Cesna pasó a manos castellanas en 1435, tal como veremos posteriormente, aunque desconocemos si fue de manera definitiva, mientras que Zagra sólo fue conquistada tras la caída de Loja en 1486. Además de estos castillos, toda una serie de torres atalayas se extendían por el sector occidental de la tierra de Loja, subsistiendo en la actualidad los restos de algunas de ellas ${ }^{8}$.

Aparte de los núcleos de población asociados a los castillos, constatamos la existencia de otros núcleos rurales que están asociados a fortalezas de menores dimensiones. Se conservan en la actualidad la torre, o más bien pequeño castillo, de Pesquera y la existente junto al cortijo de la Torre, a los pies de la sierra de Campo Agro, que nosotros identificamos con la torre de Abor citada en el Libro de Repartimiento de Loja. En ambos casos la técnica constructiva es la misma que se observa en las torres de Agicampe y Salar, es decir, mampostería ripiada formando hiladas horizontales que se remata con sillares en los ángulos rectos. La abundante cerámica existente en las proximidades de ambas torres nos induce a pensar en su conexión con núcleos de población rural, probablemente alquerías. La conquista de Iznájar en I433 debió incidir en el despoblamiento de Abor, mientras que el castillo de Pesquera fue conquistado por los castellanos en 1436, lo que nos indica que estos lugares estaban despoblados con varias décadas de antelación a la conquista de Loja. La proximidad de la frontera, unida a unas condiciones favorables desde el punto de vista geográfico, dieron como resultado que la actividad económica fundamental en esta zona fuese la ganadería, existiendo importantes dehesas (Alazores, Contarín, Marrojas) y unas salinas.

\section{Alquerías de la tierra de Loja en época nazarí}

A continuación vamos a pasar a exponer las características de cada alquería de forma individual, siguiendo un orden alfabético.

Abor.

La torre de Abor se sitúa junto al cortijo de la Torre, término municipal de Loja, cerca del

6 El castillo de Cesna ha sido descrito por ARJONA, 1979. Erróneamente, a nuestro parecer, lo identifica con el hisn Turrus citado en las fuentes escritas árabes a finales del siglo IX y comienzos del $X$.

7 Para Cesna, véase LRL, fols. 46-47; en el caso de Zagra, LRL, fols. 132 v y 139 v. En este caso se cita la existencia de "muchos olibos".

8 Es el caso de la torre de Martilla y de las atalayas existentes junto al Cortijo del Aire, Riofrío y Venta del Rayo. 
camino que desde Ventorros de la Laguna conduce a la sierra de Campo Agro. Se localiza en el Mapa Militar de España 1:50.000, 17-4 I ( I007) Rute, cuadrícula UTM 387-388/4II94120 , a una altitud de unos 690 metros.

La zona donde se ubica esta torre es una llanura arcillosa situada entre la sierra de Campo Agro y las tierras de la Dehesa de los Montes, cultivada con cereales de secano y olivos, aunque en la zona más próxima al cortijo de Balerma existen tierras de regadío.

En el Libro de Repartimiento de Loja tenemos referencias a la torre de Abor, situada en el Campo del mismo nombre, un pago donde se repartieron importantes cantidades de tierras de secano. La torre fue concedida en |49| a mosén Fernando Rejón, que también recibió una merced de 400 fanegas de tierra en el Campo de Abor (LRL, fols. 74, 74v y I36). Esta alquería se comunicaba con Loja a través de un camino que conectaba con el que unía Iznájar y Loja y que en el Libro de Repartimiento de Loja se alude a él como el "camino que biene de los Durmientes a la torre" (LRL, fol. 74 v). A pesar de que sólo se repartieron tierras de secano, algunos topónimos de la zona parecen indicar la existencia de ciertas estructuras hidraúlicas, como es el caso del arroyo de la Alberca (LRL, fol. $74 \mathrm{v}$ ) o la fuente de Malerva (LRL, fol. 76), que tal vez procede del árabe mā al-arba', "agua del miércoles", que parece aludir a un turno de riego (BARRIOS, MARTíNEZ, 1984, pp. 43-44). El topónimo Abor debe proceder del árabe al-būr, cuyo significado es el de "campo que no se labra, erial tierra non labrada", que puede hacer referencia a la ocupación de un espacio anteriormente improductivo desde el punto de vista agrícola.
Por otra parte, las referencias contenidas en el Libro de Repartimiento de Loja indican una importante actividad ganadera, así en el alindamiento de la merced concedida a Fernando Rejón leemos: "e vuelve hasta el canto de las eras e a dar en la vereda que queda para el Conzejo, para abrebadero e paso de los ganados; que an de quedar treinta pasos de la un parte del agua e otros treinta pasos de la otra parte; e a dar al baldío del dicho soto; e an de tener salida los ganados a la sierra" (LRL, fol. 74 v). Otros datos relativos a la importancia de la ganadería proceden de la toponimia, así en lugares próximos al campo de Abor el Libro de Repartimiento de Loja menciona la fuente del Hato ${ }^{10}$ y el topónimo Huévar (MALPICA, 1981, p. 53; LRL, fols. $X X X v, 73,74,74$ v, 127 y $136 \mathrm{v}$ ), que debe proceder del árabe wābar, plural de wābra, que significa "lana de cabras"”!.

La zona situada al este del Campo de Abor y que limitaba con Riofrío es conocida en la actualidad por Dehesa de los Montes, tratándose de un espacio que aún hoy en día ha conservado en determinados sectores la vegetación del monte mediterráneo, debido a que la mala calidad de estas tierras, situadas sobre un substrato de Trías de Antequera, no propicia su aprovechamiento agrícola. Esta zona es denominada en el Libro de Repartimiento de Loja como Los Durmientes'2, conservándose aún este topónimo referido a una casa existente cerca de la población de Ventorros de la Laguna. En esta zona debió ubicarse la cueva que es insistentemente mencionada por los autores árabes, sobre la cual se llegó a construir un oratorio VÁZQUEZ, 1959-1960, pp. 49-5I; FERNÁNDEZ, 1971, pp. 121-123).

\footnotetext{
9 CORRIENTE, 1988 p. 23, *bwr, s.v. 'campo que no se labra, erial tierra non labrada' bor avbár. Este topónimos es muy parecido a otro de la tierra de Loja, Arborbis, del árabe al-bawwar, que significa "terreno baldío, yermo, improductivo, barbecho", y que en árabe granadino se podría pronuncias al-bobar o al-bobir (PEZZI, 1989-1990, PP. 262-263).

10 LRL, fol. 77. Sobre la localización de este topónimo véase MALPICA, 198I, p. 5I.

II CORRIENTE, 1988, p. 213, *wbr, s.v. 'lana de cabras', guábra guábar. Sobre la utilización textil de este producto nos informa Ibn alJatib al referirse a las costumbres de los granadinos: "En cuanto á su vestimenta, la principal que usan comunmente en el inviemo son alquiceles persianos, almalafas ostentosas y otros trajes de mucho precio, de lana, lino, seda, algodón y pelo de cabra, mantos africanos y mocathas tunecinas, que se hacen de seda gruesa con vistosas labores, en el estío visten todos blancos almaizares" (SECO DE LUCENA, 1910, p. 10).

12 LRL, fols. 74 v, I 45 y I49 v. La existencia de vegetación arbórea en esta zona se deduce del siguiente texto del LRL, fol. I45: "A Pasqual Merino, un pedaço de monte para que faga una roça donde a cortado madera, ençima de los Durmientes".
} 
La torre, como hemos mencionado, se ubica en una zona llana, junto a tierras de cultivo, por lo cual pensamos que se trata de una torre de alquería. Sin duda ha perdido gran parte de su primitiva altura. Es de planta rectangular, construida con mampostería ripiada que forma hiladas horizontales, utilizándose sillares en las esquinas. En la parte inferior no conserva ninguna apertura, siendo probablemente maciza, y sólo observamos a media altura un vano bordeado con ladrillos en la cara oeste de la torre. En esta misma cara, en la esquina suroeste, se observa el arranque de un arco. Junto a la torre se conserva un espacio rodeado de muros de mampostería que está ocupado por escombros y matorrales y debe corresponder a la antigua ubicación del cortijo de la Torre. Según nos informó un vecino de la zona este edificio fue utilizado como torre de una ermita o iglesia $y$, tras su abandono, las pilas y la campana se trasladaron a la iglesia del lugar de Venta del Rayo, un anejo situado en el término municipal de Loja. A esta ocupación deben corresponder algunos añadidos 0 reformas de la torre, como los restos de enlucido o de tejas.

En los alrededores, sobre todo en las tierras cultivadas situadas frente a las caras sur y este de la torre, abundan los restos cerámicos de época romana (terra sigillata, tegulae) y medieval. Entre éstos destacan los fragmentos de cazuelas de vedrío melado, tanto de borde recto o con ligero engrosamiento al exterior, como con el borde en alero; de ataifores de vedrío melado con decoración a base de trazos de manganeso y de vedrío verde, algunos con decoración estampillada; fragmentos pertenecientes a alcadafes, uno de ellos vidriado en verde; etc. La mayor parte de este conjunto cerámico hay que datarlo en los siglos XIXIII, aunque no falta la cerámica nazarí. Al parecer procede también de esta zona una inscripción honoraria romana datada en el siglo III, por lo cual se ha llegado a decir que esta torre, aunque medieval, es de origen ibérico-romano (CARRASCO, 1986, pp. 189 y 230), aunque más bien hay que pensar que el asentamiento islámico se ubicó en donde anteriormente hubo una villa romana.
Muy próxima a los restos constructivos descritos está la fuente de la Torre, la cual, según la información de un vecino de la zona, es de carácter público y se usa como abrevadero de ganados y no para regar tierras.

\section{Agicampe.}

El cortijo de la Torre de Agicampe se sitúa en el término municipal de Loja, a los pies de la sierra del Hacho, no lejos del antiguo camino que comunicaba esta ciudad con Montefrío. Se localiza en el Mapa Topográfico Nacional de España I:25.000, 1008-III Huétor-Tájar, cuadrícula UTM 402-403/4 | |8-4| | 9, a una altitud de unos 620 metros.

La torre se ubica en una zona de suaves lomas que se encuentran situadas entre la sierra del Hacho y la Ilanura aluvial de la Vega de Huétor-Tájar, predominando el cultivo de cereales y olivos. Junto al cortijo se sitúa el manantial de Agicampe, dedicado en la actualidad al abastecimiento de agua del pueblo de Huétor-Tájar.

Ibn al-Jațîb (|3|3- | 379) alude a la instalación de ${ }^{\complement}$ Uqba b. Nu`aym, individuo árabe del yuund de Damasco, en qaryat Šikanb (IBN ALJAṬ̄B, 1976, p. 524), por lo cual cabe pensar en su existencia desde un momento muy temprano, en concreto desde mediados del siglo VIII que es cuando se produce la llegada de los aŷnad sirios a al-Andalus. Sin embargo no volvemos a tener más referencias en fuentes escritas anteriores a la conquista castellana. En el Libro de Repartimiento de Loja encontramos la mención a la torre de Agicampe, ubicada junto al regadío del mismo nombre, donde se repartieron 106 fanegas de tierra, y muy cerca del camino que comunicaba Loja y Montefrío (LRL, fols. 48 y $48 \mathrm{v}$ ). Además en los alrededores se repartieron tierras de secano (LRL, fols. $48 \mathrm{v}, 49,50 \mathrm{v}, 5 \mathrm{I}$ y $5 \mathrm{I}$ v) y se delimitó una dehesa (LRL, fol. 50 v). En 1504 nos consta que la torre estaba en posesión de Juan Alvarez Zapata por cédula real, aunque se denunció su pertenencia a la ciudad (MALPICA, I98I, p. 215). En una fuente posterior (ss. XVII-XVIII) leemos: "en el partido de Ajicampe, hay otro nacimiento que llaman la fuente de Ajicampe, de aguas muy cristalinas y 
delgadas. Está en una apasible campaña donde riega las tierras de cinco cortijos y cae al Genill' (BARRIOS, 1983, p. 62).

Los restos de la torre de Agicampe, desmochada, se sitúan junto al cortijo de este nombre, con casas adosadas a ella. Es de planta elíptica, construida con mampostería ripiada formando hiladas horizontales. Se observa en su cara este un pequeño vano a media altura.

La cerámica existente en los alrededores es escasa y está muy fragmentada, aunque se observa la existencia de un conjunto que podría datarse en época nazarí y/o en un momento inmediatamente anterior: fragmentos amorfos de piezas de cocina con vedrío melado; fragmentos de ataifores (bases con pie anular, bordes, amorfos) con vedrío verde $y$, en algún caso, melado; bordes de alcadafes sin vidriar, uno de ellos con decoración de cuerda impresa en la parte exterior del borde; etc. Diferentes a este grupo son algunos escasos fragmentos que parecen corresponder a un momento anterior, debido a la características de las pastas y su morfología, entre los que destaca un borde perteneciente a una olla de labio vuelto sin vidriar, similar a los que en principio asignamos una cronología romana.

Se pueden reconocer los restos de la estructura de regadío existente, que consiste en el trazado de una acequia que parte de la fuente de Agicampe y discurre junto a la vereda que desde el camino de Montefrío conduce al cortijo.

\section{Alfur.}

Esta alquería hay que ubicarla en la zona conocida como Los Nabos (MALPICA, 1981, p. 47) (Cortijo de los Nabos, Casa de los Nabos, Haza de los Nabos, Collado de los Nabos), en el término municipal de Loja, que se localiza en el Mapa Topográfico Nacional de España 1:25.000,
|008-I Algarinejo, cuadrícula 405-406/4 I24$4 \mid 25$, a una altitud entre 700 y 800 metros.

Esta zona se caracteriza por la existencia de tierras de labor dedicadas al cultivo de cereales en secano en el área más baja y llana y en las laderas de los montes que la circundan está presente el olivar. El aprovisionamiento de agua, según se observa en los mapas topográficos, se realiza a través de pozos.

La única referencia a este lugar es la que aparece en el Libro de Repartimiento de Loja, donde en el amojonamiento del término podemos leer: "ladera arriba fasta vnas casas derribadas que se disen Alfur, que quiere desyr alquería de los Nabillos, allí está otro mojón; e la cordillera adelante a dar al atalaia Çanax, e aguas vertientes a la parte de Taxara es de Loxa, e a la otra parte es de Montefrío" (MALPICA, 198I, p. 47).

El topónimo Alfur creemos que procede del árabe alfut, plural de lāfta, "nabo"'ls. Respecto a la atalaya Çanax hay que identificarla con el cerro del Cenacho (8I4 m.), procedente aquel topónimo del árabe granadino șanāŷ, "capacho"'14.

\section{Birmodur.}

Esta alquería debemos ubicarla en las proximidades del cortijo de los Pozos, en el término municipal de Loja, junto a un viejo camino que enlazaba Loja con Vélez-Málaga, que podemos localizar en el Mapa Topográfico Nacional de España 1:25.000, I025-I Loja, cuadrícula UTM 404-405/4106-4I07, a una altitud de 940 metros.

Este lugar se sitúa a los pies de la Sierra de Loja, en una zona donde está muy presente la vegetación natural del monte mediterráneo, aunque las zonas llanas próximas a los corti$j$ s $^{15}$ se dedicaban tradicionalmente al cultivo cerealista de secano, sustituido hoy en día por

13 CORRIENTE, F. (1988): El léxico árabe andalusí según P. Alcalá, p. 185, *ilt, s.v. nabo ortaliza léfte left. No recoge este plural. 14 CORRIENTE, F. (1988): El léxico árabe andalusí según P. de Alcalá, p. 120, *snc, s.v. 'capacho de molino de aceite' çanách çanánich. I5 Además del cortijo de los Pozos se ubican en esta zona desde antiguo, constatándose ya en los siglos XVIII-XIX, los cortijos del Ángel y del Cardador, topónimo este último que revela la importancia de la actividad ganadera de los cortijos existentes en esta zona. 
los cultivos de olivos y almendros. Hay que destacar por otra parte que la sierra de Loja es un espacio dedicado al aprovechamiento ganadero, donde las únicas construcciones existentes son las majadas para el ganado.

Esta alquería es mencionada en el Libro de Repartimiento de Loja en el deslinde del término de esta ciudad: "comienza el primer moxon en la sierra de Salar; e de alli va derecho a dar al otro mojon que esta en una cornicabra zerca de unos allozos, mas çerca del poço que se diçe de Bilmodan, que esta junto con el camino biejo de la sierra que ba a Zalea; e aguas vertientes a la parte del pozo es termino de Alhama e las vertientes a estotra parte es termino de Loxa; e tomar alli abaxo fasta juntar con una alcaria que se dize Bilmodan, e la cañada abaxo a dar a un zerro grande en una loma do esta un zimiento antiguo, e en medio de el esta otro moxon" (LRL, fol. XXVIII v).

Respecto al topónimo, Bilmodan es la variante que aparece en una copia del siglo XVII, pero las variantes más fieles al original árabe son Birmodur o Bilmodur, cuya etimología árabe podría ser bīr al-mudūr, "pozo de las casas"'|6.

\section{Frontil.}

El manantial de Frontil se ubica en el término municipal de Loja, junto a la carretera de Priego, localizándose en el Mapa Topográfico Nacional de España 1:25.000, 1008-III HuétorTájar, cuadrícula UTM 399-400/4 | I5-4 I I6, a una altitud de unos $500 \mathrm{~m}$.

La zona donde se ubica presenta tres elementos: la sierra del Hacho, a sus pies una zona de suave pendiente donde se ha desarrollado el cultivo del olivar y a continuación una llanura aluvial que es regada con las aguas del manantial de Frontil y con las de otros existentes en las laderas de la sierra.

El topónimo al-Funtayn, que se viene identificando con el actual Frontil, aparece citado en las fuentes escritas árabes como el lugar donde se instaló a mediados del siglo VIII 'Abd Allāh b. Jālid, un personaje árabe ${ }^{17}$ que había recibido en esta zona una propiedad agrícola (dayca) donada por Artobás, noble hispanovisigodo, hijo del rey Witiza, que había heredado parte del patrimonio de los monarcas visigodos ${ }^{18}$. Nos consta que 'Abd Allāh b. Jālid se instaló en este lugar' ${ }^{19}$, convirtiéndose en un asentamiento tribal, como se observa cuando a fines del siglo IX las fuentes árabes que narran el enfrentamiento entre el Estado cordobés e Ibn Hafșūn citan a al-Funtayn como hișn de los Banū Jālid ${ }^{20}$, clan del que surgió un nutrido grupo de funcionarios administrativos y militares vinculados al poder omeya de Córdoba, sobre todo durante el emirato de 'Abd Allāh"1. La siguiente mención a este lugar que encontramos en las fuentes escritas corresponde al siglo $X V$, en concreto la Crónica del Halconero de Juan II al referirse a la incursión del condestable Alvaro de Luna en |431 por territorio granadino cita a Frontí como una de las aldeas atacadas, de la cual se dice que era de la "infanta Arnalmao" (CARRILLO, 1956, p. 100). Por el Libro de Repartimiento de Loja sabemos que existía una torre ubicada en las proximidades del regadío de Frontil (LRL, fol. 52 v). Según se deduce de este texto la acequia que desde el manantial

16 No hemos encontrado la forma mudur, pero podría tratarse de un derivado de la palabra dur, plural de dar "casa".

17 Un antepasado suyo, 'Amr, había sido mawlà del primer califa omeya đUțān b. 'Affān (644-656), según se deduce de las genealogías de sus descendientes (cfr. CASTILLA, 1992, p. 222, donde se alude a la muerte en el año 93। de Abū I-Ŷ́acd Aslam, descendiente de 'Abd Allāh b. Jālid). Sabemos también que junto a su primo Abū Uțmān b. UUbayd Allāh b. Uțān, que residía en qaryat Ṭurruš, también cerca de Loja, participó activamente en la llegada de 'Abd al-Rạhmān I a al-Andalus en el año 755 (Ajbār Mậmū‘a, ed. y trad. E. Lafuente Alcántara, Madrid, 1867, p. 76). Cfr. FIERRO, 1990, p. 52

I8 Ibn al-Qūțiyya, Ta'rij Iftitāh al-Andalus, trad. en VALLVÉ 1986, pp. 200-202.

19 "...se retiró á su casa de Alfontin, donde permaneció hasta su muerte, sin aceptar cargo ninguno del sultan" (Ajbār Maŷmūca, p. 98).

20 "Al-Muqtabis de Ibn Hayyān”, trad. J.E. Guráieb, Cuademos de Historia de España, I7, 1952, año 275 (888-889), p. I58; 23-24, 1955, año 278 (89|-892), p. 342; 25-26, 1957, año 28। (894-895), p. 337. En esta traducción este topónimo aparece citado como al-Famatina, Fontana y al-Fontin respectivamente.

21 Sobre varios miembros de los Banu Jalid nos informa Ibn Hayyan al narrar los acontecimientos de los años 275 (888-889)-276 (889890): "Al-Muqtabis de Ibn Hayyan", trad. J.E. Guráieb, Cuademos de Historia de España, 17, 1952, pp. I58 y 16I-162; I8, 1952, p. I55; I9, 1953, pp. 155 y |6I-I62. 
discurre hacia el oeste es la que abastecía de agua a las huertas de la ciudad de Loja existentes en esta zona ${ }^{22}$, mientras que la acequia que se dirigía hacia el este regaba una menor porción de tierras que no son denominadas huertas ${ }^{23}$. Además se alude a la concesión de "un edifiçio de molino en Frontil" al comendador Alonso de la Peñuela (LRL, fol. 107). Por esta zona pasaban los caminos que desde Loja conducían a íllora y Montefrío (LRL, fol. 8 I v).

La prospección arqueológica superficial llevada a cabo en la zona nos ha permitido constatar la existencia de un importante asentamiento romano, conocido desde el siglo $X \mid X^{24}$, al sur de la ermita de la Esperanza, dada la gran abundancia de cerámica tanto común como terra sigillata encontradas, así como tegulae. Por otra parte existen estructuras excavadas en la roca, destacando una necrópolis. No obstante este predominio aplastante de cerámica romana, también hemos recogido en esta zona algunos fragmentos de cerámica medieval que pueden corresponder tanto a una cronología almohade como nazarí: fragmentos pertenecientes a piezas de cocina de vedrío melado; otros de vedrío melado claro y verde que deben corresponder a ataifores; borde de alcadafe; fragmentos pertenecientes a tinajas con decoración a base de cordones con incisiones; etc. A modo de hipótesis, creemos que la ermita de la Esperanza, en torno a la cual se ha formado un importante barrio, es la torre existente en época nazarí.

También hemos comprobado la importancia de las estructuras hidráulicas existentes en la zona, algunas de ellas aún en uso, como ocurre con las acequias, otras ya abandonadas, como en el caso de los restos de lo que fue el molino alto de Frontil o una gran alberca denominada estanque Muela, que, según las noticias proporcionadas por un vecino de la zona, recogía el agua de un manantial que surge en la ladera de la sierra del Hacho y se destinaba a regar las tierras de los cortijos del Viso y las Peñuelas, situadas por encima de la acequia que del manantial de Frontil se dirige hacia el oeste. Hoy en día este sistema se ha sustituido por una conducción de tubos subterráneos.

\section{Gibralpulpo.}

Creemos que esta alquería debió ubicarse en las proximidades del actual cortijo de la Artichuela, en el término municipal de Loja, cercano al núcleo de Fuente-Camacho y a la sierra de Gibalto. Este cortijo se localiza en el Mapa Topográfico Nacional de España 1:50.000, 1024 Archidona, coordenadas $4^{\circ} 14^{\prime}$ de longitud oeste y $37^{\circ} 05^{\prime}$ de latitud norte, a una altitud de unos 790 metros.

La zona donde se ubica este cortijo se caracteriza por un paisaje alomado, existiendo una pequeña zona irrigada gracias a las aguas de una fuente que nace cerca del cortijo, mientras que en el resto de la zona predominan en las áreas más llanas los cultivos de cereal de secano, en tanto que en los montes y zonas con pendiente se ha desarrollado el cultivo de olivos y almendros.

Creemos que en este lugar debió ubicarse una alquería por el hecho de encontrarnos, como en otras zonas de la tierra de Loja donde existen núcleos de población rural, con la mención de una torre junto a espacios cultivados, normalmente de regadío. En el Libro de Repartimiento de Loja podemos leer en referencia a una partida de 25 fanegas repartidas en esta zona a un vecino de Loja: "alinda con un

\footnotetext{
22 “...repartimiento de las viñas e huertas que estan rebueltas, que ai en ellas muchos arboles frutales, a la parte de Frontil” (LRL, fol. 3I).

23 "...repartimiento de las tierra de regadio en Frontil, de aquella parte de la torre fasta la foia donde se acaba el dicho regadio" (LRL, fol. 52 v)

24 E. Lafuente Alcantara en referencia a la localización de al-Funtayn nos dice: "Parece casi seguro que estaba este pueblo en las ruinas que hay en el pago del Frontil, como a media legua al norte de Loja y a la otra parte del río, en el camino de Montefrío, donde brota un buen golpe de agua. Hace poco que allí se descubrieron varios trozos arquitectónicos y un busto de Ariadna, que posee el Sr. Fernández Guerra. Es sitio fuerte por su naturaleza" (Ajbār Maŷmūca, índice geográfico, p. 245). Más recientemente M. Pellicer, a raíz de las prospecciones llevadas a cabo en la zona de Loja en 1957 y 1959, escribe: "I00 m. al sur de la ermita de la Esperanza, un yacimiento romano imperial con abundantes tegulas y terra sigillata. Tumbas excavadas en la roca, de planta trapezoidal alargada y extraordinariamente estrecha" (PELLICER, 1962, pp. 330-331).
} 
torrejon caido, que esta cave la guerta de Gibralpulpo" (LRL, fol. 62). La identificación de esta huerta con el cortijo de la Artichuela nos parece plausible teniendo en cuenta que esta zona se conoce como Llano de la Hortichuela, además en una descripción de las fuentes de la tierra de Loja en la época moderna se menciona una "fuente que llaman de Mari Sanches, que está por encima del cortijo de la Ortichuela" (BARRIOS, 1983, p. 58). A pesar de la mención a la "guerta de Gibralpulpo" en el Libro de Repartimiento de Loja en esta zona no se menciona ningún repartimiento de tierras de regadío, tan sólo se entregaron importantes cantidades de tierras de secano. Habría que señalar, en otro orden de cosas, que esta zona se sitúa en el punto de encuentro de importantes elementos relacionados con la ganadería, como es el caso de las Salinas (MALPICA, 199I, pp. 799I), lugar donde en el Libro de Repartimiento de Loja se alude a la existencia de una dehesa (LRL, fol. $63 \mathrm{v}$ ) y corrales (LRL, fol. 61 ), o de las dehesas del Contarín y Alazores ${ }^{25}$, topónimo este último relacionado con la ganadería, ya que en la primera documentación castellana aparece citado como "campo de Aynaçof" (MALPICA, QUESADA, 1993, doc. 60, p. I4I), del árabe 'ayn al-șūf, "fuente de la lana".

La prospección llevada a cabo en las proximidades del cortijo de la Artichuela ha proporcionado escasa cerámica, que parece corresponder a época romana, con excepción de dos fragmentos: un borde de ataifor de vedrío melado con decoración de trazos de manganeso y un borde de disco o tapadera.

También hemos constatado la existencia de una gran alberca, hoy en desuso, que era utilizada como colector-distribuidor del agua de la fuente existente en las proximidades del cortijo.

\section{Huétor.}

Esta alquería se situó donde hoy está el pueblo de Huétor-Tájar, que se localiza en el
Mapa Topográfico Nacional de España |:25.000, 1008-III Huétor-Tájar, cuadrícula UTM 407-408/4 | |7-4 | |8, a una altitud de 487 m.

Este pueblo se sitúa junto al río Genil, contando con una amplia vega de regadío que, en gran parte, ha sido creada recientemente, ya que hasta mediados del presente siglo la única zona de regadío era el actual pago de La Veguilla, que aprovechaba las aguas del arroyo Vilano, quedando el resto de la llanura aluvial para cultivos cerealistas de secano.

La qaryat Wāt citada por Ibn al-Jațīb (|313-1374) (IIMÉNEZ, 1990, p. 82) no debe relacionarse con este Huétor, sino con Huétor-Santillán, que en la documentación castellana de fines del siglo XV y principios del $\mathrm{XVI}$ aparece denominada como Huete ${ }^{26}$. A falta de esta referencia, la primera cita de Huétor en las fuentes escritas la encontramos en el relato que la Crónica del Halconero de Juan II hace de la campaña del condestable Alvaro de Luna en 1431, donde se cita a Hector o Vector, como una de las aldeas destruidas (CARRILLO, 1946, p. 100; Cfr. CARRIAZO, 197I, pp. 29-84). En el Libro de Repartimiento de Loja encontramos referencias a la torre de Huétor, situada junto a las tierras de regadío y secano del denominado Campo de Huétor, por donde cruzaba el camino de Loja a Íllora (LRL, fols. 49, 49 v y 50). En concreto, en los alrededores de la torre el alcaide de Loja, Alvaro de Luna recibió 400 fanegas de regadío y secano, uno de cuyos lindes era "el açequia alta" (LRL, fols. I37 v y 138), a las que hay que sumar las que fue comprando posteriormente hasta conformar un señorío territorial (MALPICA, 1981, pp. 350-358). Los Reyes Católicos concedieron en 1496 a este personaje la torre y cortijo de Huétor, fundando posteriormente un mayorazgo, culminando este proceso con la concesión a los Luna del señorío jurisdiccional en 1559 por 5.000 ducados. La iniciativa de Alvaro de Luna para

25 "Quedo por medir el campo de Zafaiona, dende el rio de Cazin e lo del Contaril e campo de Añazor e otros lugares lexos de la çiudad que no son para labor salvo para baldios de ganados" (LRL, fol. XXXII).

26 SECO DE LUCENA, 1964, p. 323 identificó esta alquería con Huétor-Tájar, llevando a una equivocación a otros estudiosos posteriores. En cambio A. Díaz García ya ha señalado que probablemente haya que identificarla con Huétor-Santillán (DÍAZ, BARRIOS I99I, p. 212. 
poner en explotación sus tierras fue atraer población mudéjar, firmando una capitulación en 1497 con Hamete Gerafi, alfaquí, moro vecino de Granada, y Abraen Antique, alguacil musulmán de Huétor y Tájar (MALPICA, 1981, pp. 350-358; BARRIOS, 1986). En I 5 I 2 la población de Huétor se estimaba en unos 80 vecinos (SÁNCHEZ RODULFO, 1987, p. 127), cifra que está en la línea de otros datos conocidos, así en 1568 la población morisca poseía un total de 79 casas. En este momento la topografía del lugar estaba definida por la existencia del fuerte, el barrio alto y el barrio nuevo (BARRIOS, 1986).

El único elemento existente en el actual pueblo que merece la pena citar es un edificio a modo de torre, de cronología desconocida, cuya ubicación debe corresponder a la de la torre existente en la época nazarí.

\section{Pesquera.}

Los restos de la torre de Pesquera se emplazan junto al arroyo del mismo nombre, en el término municipal de Algarinejo, localizándose en el Mapa Militar de España |:50.000, |7-4| (1007) Rute, cuadrícula UTM 393-394/4I25-4I26, a una altitud de unos 440 metros.

Se ubica esta torre en el estrecho valle del río Pesquera, cuyo fondo de depósitos aluviales es regado por las acequias que, a la altura de la torre, derivan del río. En las laderas del valle encontramos tanto vegetación arbustiva mediterránea en las zonas con más pendiente y pedregosas, como un desarrollo creciente del olivar, que está suplantando a antiguas tierras calmas de labor.

Sobre el lugar de Pesquera tenemos tempranas referencias escritas, puesto que aparece en documentos castellanos del siglo XIII relacionados con la implantación castellana en los vecinos territorios del subbético cordobés. Un documento de 1253 hace referencia a que el maestre de Calatrava dio en tenencia a Arias Pérez el castillo de Algarín, situado entre Pesquera y Priego, con el fin de que lo poblase ${ }^{27}$. Otro documento de I262 menciona a "Mohamat aben alí Alcancan y Mahomat aben Hyar, moros de Pesquera" entre aquellos enviados por el rey de Granada para ayudar a los castellanos en la delimitación del término de Tiñosa (NIETO, 1980, doc. 637), castillo que se ubicaba entre Priego y Rute, en la actual provincia de Córdoba ${ }^{28}$. Las siguientes noticias sobre Pesquera en las fuentes escritas son relativas al siglo XV. Un documento de I442, recogido en la Historia de la Casa de Córdoba, por el que se concede a Diego Fernández de Córdoba la villa de Cabra, dice: "E por quanto el dicho Diego Fernández de Cordova Mariscal faciendo señalados servicios al dicho Señor Rey gano la villa de... e el Castillo de Pesquera de los Moros del Reyno de Granada en los años de 1435 e de 1436" "FERNÁNDEZ DE CÓRDOBA, 1958, p. 252). A esta conquista alude también una carta de 1470 , que el hijo del conde de Cabra envía a su rival don Alonso de Aguilar, donde podemos leer: "et vos sabés bien como el conde mi señor ganó la villa de Cexua (sic) de los moros por conbate y el castillo de pesquera" (LAFUENTE, I868, pp. 94-95). Por ello en la tregua de 1439 se cita a Zixna y Pesquera entre los lugares que los castellanos habían conquistado recientemente (GAMIR, 1956, pp. 56-57). La conquista de ambos lugares fue posibilitada por la conquista definitiva de Iznájar en 1433 por los castellanos. En el Libro de Repartimiento de Loja no se alude al reparto de tierras en esta zona, tan sólo en la zona próxima a la desembocadura del río Turcal, actual arroyo Pesquera, en el río

\footnotetext{
27 La regesta del documento es la siguiente:

1253, marzo, 28. (s.l.) El maestre de Calatrava, queriendo repoblar, da en tenencia para los días de su vida a Arias Pérez el castillo de Alganín, situado entre Pesquera y Priego, con el fin de que lo poblase y labrase según fuero de Priego, reservándose el diezmo que pagarían los pobladores. (NIETO 1979, doc. 423).

${ }^{28}$ ARJONA, 1985, pp. 89-104. El castillo de Tiñosa fue abandonado y destruido por los castellanos en 1280 por ser muy costoso su mantenimiento y por los continuos ataques de los moros de Rute. Creemos que el castillo de Algarín debió sufrir un destino similar, teniendo en cuenta que en los siglos XIV y XV no es mencionado en las fuentes escritas y que no hay evidencias de su posible ubicación, con la excepción de su situación en las proximidades del pueblo de Algarinejo.
} 
Genil, sin duda a partir de la Cerradura. La documentación castellana de principios del siglo XVI menciona la pesquería de Turca (MALPICA, 1981, p. 452, nota 313), actividad a la que también hace referencia el topónimo de esta torre y que es descrita por Madoz en el siglo $X \mid X^{29}$.

La torre de Pesquera, considerada habitualmente como atalay ${ }^{30}$, se sitúa en un espolón rocoso existente junto al río Pesquera. Es de planta ultrasemicircular, construida con mampostería ripiada formando hiladas horizontales. Entre los mampuestos se observan también algunos fragmentos cerámicos estampillados pertenecientes a tinajas. La zona baja de la torre es maciza, conservándose en la planta superior restos de una bóveda. De hecho la torre no es el único elemento defensivo existente, sino que cierra el tramo del espolón rocoso más próximo al río, de modo que queda una zona para refugio de la población, la cual además está reforzada por mampostería que hace totalmente verticales las paredes del peñón. En los ángulos rectos del muro que parte de la torre para cerrar la entrada al recinto de refugio hay colocados sillares. Así se puede entender la alusión en la documentación a este lugar como castillo. A su vez esta mayor complejidad induce a pensar que no se trata de una simple atalaya; por otra parte, su ubicación en el valle del río tampoco hace factible esta función ya que la visibilidad es muy limitada. Otro aspecto a destacar es que en la fachada sureste se conservan restos de un falso aparejo, que diseña formas cerradas con líneas curvas, además de presentar pequeñas piedras incrustadas; algo semejante a lo que ocurre en el castillo de Vélez de Benaudalla, edificado a finales del siglo XV (CRESSIER, 1988, pp. 101-103), por lo cual podemos pensar que el enlucido de la torre de Pesquera responde a reparaciones realizadas por los castellanos en el siglo XV.
La alusión a "moros de Pesquera" en el siglo XIII y las características del espacio en el cual se ubica la torre nos llevan a avanzar la idea de que se trata de una fortaleza vinculada a una alquería. De hecho, a los pies del espolón rocoso donde se sitúa, al sur, aparecen junto a algunos restos de muros de mampostería vinculados a un cortijo derruido, gran cantidad de fragmentos de cerámica que en su conjunto pueden datarse en la época nazarí (siglos XIII-XV): fragmentos de bordes de cazuela con vedrío melado y labio en alero; bordes rectos de marmitas con incisión en la unión cuerpo-borde y reborde al interior para tapadera; fragmentos pertenecientes a ataifores de vedrío verde, uno de ellos estampillado, siendo escasísimos los de vedrío melado; un fragmento de cuerpo de jarrita de pasta clara con decoración a base de goterones de vedrío verde; fragmentos de tinajas estampilladas; bordes de alcadafes; etc.

\section{Plines.}

Creemos que en el actual pago de Plines, término municipal de Loja, se ubicó una alquería, cerca del Molino de la Torre, que se localiza en el Mapa Topográfico Nacional de España I:25.000, I008-III Huétor-Tájar, cuadrícula UTM 395-396/4 | |4-4 I I5, a una altitud de unos 490 metros.

El pago de Plines es una llanura aluvial dedicada a cultivos de regadío que se nutren con las aguas procedentes del manantial del mismo nombre.

En el Libro de Repartimiento se alude a la existencia de una torre junto a las tierras cultivadas del regadío de Plines ${ }^{31}$. Esta ubicación, que es normal en otras torres de alquería de la tierra de Loja, nos induce a pensar en la existencia de una alquería vinculada a esta fortaleza. Sabemos además que le fue dada a Juan Pérez de Valenzuela en I 492 "la torre de

\footnotetext{
29 “...y dejando todas sus particulares denominaciones toman el nombre de r. Pesquera, derivado sin dudad de las grandes pesquerías de bogas que desde este sitio se hacen hasta el de la Boquilla, por donde desagua en el Genil' (MADOZ, 1987, s.v. Algarinejo).

30 Referencias a la torre de Pesquera en LÓPEZ, 1990, p. 20; MADOZ, 1987, s.v. Algarinejo; TORRES, 1974; MALPICA, 1987, p. 970; ROMERO, ROSA, 1986, p. 128.

31 "En estos cavalleros se acabo el regadio de Plines, que començo dende la pasada de Riofrio, biniendo a la çiudad, a la mano izquierda, fasta el rio de Plines, en drecho de la torre" (LRL, fol. I00)
} 
Plines con los edificios de los molinos" (LADERO, 1988, p. 125, merced no 378), lo cual nos afirma en localizar dicha torre en las proximidades del actual Molino de la Torre.

La prospección que hemos realizado en la zona no nos ha dado resultados positivos, en cualquier caso se comprueba la importancia de las estructuras hidráulicas, como ocurre con el molino de la Torre, sobre el cauce del arroyo de Plines, situado junto al camino viejo de Iznájar, además de observar que las cuevas de Plines, citadas en el Libro de Repartimiento, han estado habitadas hasta tiempos muy recientes, por lo cual no hemos hallado restos cerámicos que nos hubieran permitido datar una posible ocupación en época medieval.

\section{Salar.}

El lugar de Salar, cabeza de un municipio, se localiza en el Mapa Topográfico Nacional de España 1:25.000, I025-I Loja, cuadrícula UTM 405-406/4 I I 2-4 I I3, a una altitud de 547 metros.

Este pueblo se ubica en el valle del arroyo de Salar, que a pesar de ser un curso de agua muy escaso ve incrementado su caudal con una serie de nacimientos que posibilitan el riego de su llanura aluvial, mientras que en las laderas del valle los tradicionales cultivos herbáceos de secano han desaparecido en favor del olivar en los últimos tiempos.

Ibn al-Jatīib alude a una alquería llamada alŠalàr, que se viene identificando con el pueblo de Salar (SECO DE LUCENA, 1974, p. 7I), pero creemos que esta relación no es correcta ya que, por una parte, las alquerías mencionadas por el polígrafo granadino son aquellas ubicadas en el alfoz de Granada y, desde luego, la alquería de Salar estaba ubicada en el distrito de Loja; por otra parte, Ibn al-Jatịb la cita junto a las de Duwayr (Dobaire, pago en el norte del término de Granada), Marasana (Maracena) y Tignar (Tignar, pago de Albolote) ${ }^{32}$, por lo cual cabe pensar que la alquería citada por este autor se ubicaba inmediatamente al norte de la ciudad de Granada y no en las proximidades de Loja. En la Crónica del Halconero de Juan II se cita a Salar como uno de los lugares atacados por las huestes del condestable Alvaro de Luna en |431: "... entre los quales fué quemado vn logar que dezían El Salar, que era de doçientos vezinos" (CARRILLO, 1956, p. 98). En alguna de las narraciones de la Guerra de Granada se alude a la fortaleza de Salar (FERNÁNDEZ DE CÓRDOBA, 1961, p. 312).

El protagonismo de Fernando del Pulgari3 en la conquista de este lugar en I 486 le llevó a ser nombrado alcaide de su fortaleza con 70.000 maravedíes de tenencia, hasta que fue mandada derribar en abril de 1498 (LADERO, 1988, pp. 218-219). En cuanto a las noticias procedentes del Libro de Repartimiento de Loja, encontramos una interesante alusión a unas casas "en el arrabal de Salar" (LRL, fol. I 32 v, nota al asiento $\left.n^{\circ} 2569\right)$, a la vez que se describen algunos elementos de sus sistema de irrigación (presa, acequias) (LRL, fols. I30-I30 v) y se menciona la existencia de olivares en el regadío ${ }^{34}$. A partir de una merced de 520 fanegas de regadío y secano concedida a Fernando del Pulgar se fue configurando un señorío territorial en el cual se favoreció el asentamiento de población mudéjar, como en el caso de Huétor, concediéndole los Reyes como merced la torre y cortijo de Salar en 1500 (MALPICA, 198I, p. 26). Doce años después se cita la existencia de entre 15 y 17 vecinos en Salar (SÁNCHEZ RODULFO, 1987, p. 127). Del mayorazgo establecido en 1526 (CARRIAZO, 197।, pp. 5I0-5II) se pasó posteriormente a la concesión del señorío jurisdiccional.

En la actualidad se conserva entre las casas del pueblo una torre de gran tamaño de planta rectangular, situada junto al palacio del marqués

\footnotetext{
32 Sobre la localización de estos topónimos véase JIMÉNEZ, 1990, pp. 187-188, 221 y 270-27I.

33 Sobre este personaje véase CARRIAZO, 197I, pp. 497-536.

34 "A estos cupo el postrer niego del olivar, en pasando el vado de Salar, a la mano izquierda, a la parte de Loxa" (LRL, fol. 56v. "...e el açequia adelante, por çima de los olivares" (LRL, fol. I30).
} 
de Salar y también muy próxima a la iglesia. La torre sigue la misma técnica de construcción que en la mayoría de la torres de alquería de la tierra de Loja, es decir, está construida con mampostería ripiada dispuesta en hiladas horizontales, utilizándose sillares en las esquinas. En la parte superior presenta almenas.

\section{Tájara.}

La alquería de Tájara se ubicó donde hoy se sitúa la casería de Las Torres, término municipal de Huétor-Tájar, que podemos localizar en el Mapa Topográfico Nacional de España 1:25.000, 1008-III Huétor-Tájara, cuadrícula UTM 408-409/4 | | 8-4 | I 9, a una altura de unos 495 metros.

Este lugar se sitúa en la zona de contacto entre las tierras arcillosas situadas al Sur, dedicadas en la actualidad al cultivo en secano de cereales y olivos, y las zonas aluviales existentes en los márgenes de los ríos Genil y Cacín, regadas con las aguas de este último curso fluvial a través de la denominada Acequia de Riego del Cacín.

La primera mención a este topónimo en las fuentes escritas se encuentra en el texto de al-Udri (I003-1085) relativo a la división administrativa de la cora de llbira, uno de cuyos distritos era el "iqlīm al-Tāŷarat, es decir, Tāâyarat al-Ŷabal, Taŷarat al-Wādī y Taŷaārat al-Laŷam" (JIMÉNEZ, 1990, p. 57). Esta primera mención plantea ya algunas polémicas como las relativas al significado exacto del término iqlimm ${ }^{35}$ o la localización de estos lugares, ${ }^{36}$ pero no creemos oportuno extendernos ahora en estas cuestiones que se resuelven con meras hipótesis. Sí nos parece importante señalar que la existencia de tres lugares denominados del mismo modo con la variante de su situación geográfica (Tájara del Monte, Tájara del Río y
Tájara del Llano) parece ser el resultado de una segmentación de tipo tribal. Las siguientes menciones a este topónimo aparecen en dos obras de Ibn al-Jațîb (13/3-1374) y son también relativa al iqlīm Tâŷarat al-Ŷabal (IIMÉNEZ, 1990, pp. 58 y 260). Siguiendo la propuesta de Seco de Lucena (SECO DE LUCENA, 1964, p. 326) se ha identificado una de las alquerías citadas por lbn al-Jațib en la Ihata, entre aquellas pertenecientes al patrimonio de los sultanes granadino, con Tájara: "Qaryat Tāŷara, patria de Faḍl b. Maslama al-Hasanī, con un hișn y en sus alrededores un rabad (arrabal) muy poblado" (JIMÉNEZ, 1990, p. 82). No obstante creemos que esta identificación habría que revisarla, junto a la de todas las alquerías citadas en esa misma relación de lugares, ya que probablemente son grafías erróneas que habrá que relacionar con lugares que sí sabemos con certeza que pertenecían al patrimonio real nazarí como Roma, Cijuela, Asquerosa, Huete, Beas, etc.

Las fuentes escritas castellanas aluden a la villa y fortaleza de Taxara en la época nazarí, concretamente es mencionada en las crónicas como consecuencia de las incursiones castellanas en la zona durante el siglo XV. A través de los datos contenidos en estos textos podemos aproximarnos al conocimiento del mecanismo defensivo de las alquerías nazaríes.

En |431, según la Crónica del Halconero de Juan II, las huestes del Condestable Don Alvaro de Luna, tras atacar íllora y varias aldeas de la Vega de Granada establecen su "real" cerca de "vna villa que dizen Táxara". La Crónica continúa diciendo: "Essa noche que ay asentamos real fué entrado el dicho lugar, e fué començado a quemar; e otras algunas aldeas que estabas desta parte fueron quemadas". Al día siguiente se continuó el ataque a este

\footnotetext{
35 Al--Udnrī al enumerar los distritos de la cora de llbira usa los términos iqlīm y $\hat{y} u z '$. H. Munis consideraba el iqlīm como una unidad administrativa y fiscal con una economía basada en la agricultura intensiva, mientras que el ŷuz' sería un área comunal exenta de impuestos y con una dedicación ganadera (MUNIS, 1957, pp. I21-122). Sin embargo esta distinción no tiene sentido si tenemos en cuenta la redefinición del término $\hat{y} u z^{\prime}$ realizada por P. Cressier para el caso de la Alpujarra, donde se presenta como un distrito compuesto por varias alquerías dedicadas tanto a la agricultura intensiva como a la ganadería y que están vinculadas a un castillo (CRESSIER, I984, pp. I79199).

36 Sobre este tema véase SECO DE LUCENA, 1964, p. 326; y JIMÉNEZ, 1990, pp. 267-268; nos parece acertada la opinión de esta autora cuando dice: "Creemos que al-Udri no pretende enumerar formas toponímicas compuestas por la voz Tayara, sino que refiere tres entidades adscritas a un mismo iqlïm y que, lógicamente, deben de estar próximas entre sî'.
} 
lugar: "E estubieron ay las batallas fasta que se entró el logar e se acabó de quemar. E fueron talados muchos panes que ay abía; e no nos detubimos sobre la fortaleza porque teníamos otro día de pasar vn río malo, e porque no era tal que tomada se pudiese detener" (CARRILLO, 1956, pp. 97-98).

Respecto a la conquista y destrucción de Tájara en I483, en la Crónica de Fernando del Pulgar se lee que en este año, tras atacar Íllora y Montefrío, las tropas del rey se dirigen a Tájara, lugar perjudicial para el mantenimiento de Alhama. Una vez allí decide combatir la "villa" y las gentes del lugar "no pudiendo sofrir los combates que les fueron dados, desampararon la villa, é los que pudieron se retraxeron a la fortaleza". Una vez "entrada" la villa, los cristianos dudan entre tomar o no la fortaleza, debido a que "el muro era muy fuerte". Finalmente se decide combatirla, ya que "se habian recogido en ella tantos moros é moras de los viejos é criaturas, que no podian tener mantenimientos para se sostener, é que la turbacion que tenian de ver tomada la villa, les quitaria las fuerzas para defender la fortaleza". Las tropas castellanas se dividieron en cuatro grupos atacando respectivamente "una parte del castillo", "otra parte", "una de las torres que estaban á la puerta de la fortaleza" y "otro pedazo de lienzo de la cerca". La defensa de los moros ("tiraban piedras, é tiros de pólvora, é saetas desde los muros é torres... echaban de arriba manojos de lino é de cañamo, bañados en azeyte é pez ardiendo") les permitió mantenerse ese día en la fortaleza. Al día siguiente los castellanos endurecieron el asedio al castillo, de tal modo que los musulmanes pidieron negociar, enviando "un alfaquí al Rey, á les ofrescer el castillo, si le ploguiese dar seguridad de la vida, é libertad de las personas é bienes á los que en él estaban". No aceptó Fernando el Católico esta propuesta, de modo que "algunos de los moros veyendo que no se podian defender, acordaron de se dar á prision; otros decian que debian morir en la defensa del castillo". Esta división favoreció la conquista final de la fortaleza: "los christianos ovieron lugar de entrar por fuerza el castillo, é pusieron encima del muro la señal real, é prendieron todos los moros é moras, é fueron robados gran cantidad de bienes, é bastimentos, é armas, é caballos que en él estaban". Tras la conquista, el rey "mandó poner fuego á la villa, é derribar los muros de la fortaleza" (PULGAR, 1953, pp. 387-388).

De los asedios a Tájara de |43| y |483 se deduce que la "villa", es decir las casas, debía tener un cierto dispositivo defensivo, tal vez una pequeña muralla. También podemos observar el carácter de refugio para la población que tiene la fortaleza, que era una estructura bastante compleja. En la narración de Pulgar se observa que las decisiones que toman los habitantes de Tájara no están mediatizadas por un personaje en concreto, se habla siempre en plural, incluso cuando se decide negociar con los castellanos se envía a un alfaquí, probablemente en representación del conjunto de la comunidad, o, más concretamente, de sus miembros más prestigiosos. En este mismo sentido parecen situarse los testimonios procedentes de otras zonas del reino, así, por ejemplo, las capitulaciones para la entrega de la "villa" de Alfacar, son asentadas con los alcaides de las torres, pero se especifica que se hace "por sy é en nombre de los alguaziles, alcadís, alfaquíes, é viejos é buenos onbres, chicos é grandes, machos é hembras, de la villa de alfatar" (GARRIDO, 1992, p. 307). Otro aspecto destacable es el hecho de que en 1432 este lugar, debido a que había apoyado al sultán Yusuf IV b. al-Mawl, partidario de la paz con Castilla, acogió a las huestes castellanas que realizaban una incursión contra Muhammad IX, vendiéndoles pan y otras vituallas (SECO DE LUCENA, 1978, p. 142). Esta actitud tal vez revela que los habitantes de estas zonas castigadas a menudo por las incursiones militares castellanas, que se dedican fundamentalmente a destruir las cosechas, son los más interesados en que existan buenas relaciones entre castellanos y granadinos.

Pasando a otra temática, hay que señalar que la información contenida en el Libro de Repartimiento de Loja nos va a permitir aproximarnos al espacio vinculado a la alquería de Tájara. El elemento más destacado es sin duda la larga acequia que deriva del río Cacín y que en el citado texto se menciona como "el açequia gorda del rio de Caçin que biene a Taxara" (LRL, fol. I 40 v). Esta acequia hace posible la existencia de un amplio espacio irrigado (LRL, 
fols. 83 v-92 bis v y 145- 149) que sin duda motivó la prosperidad de esta alquería y el hecho de que los castellanos la mencionen como "villa". El cauce del Genil debió ser más amplio que en la actualidad y estaría ocupado por una vegetación de ribera, existiendo la amenaza de inundación, así en el Libro de Repartimiento encontramos una alusión al repartimiento de "un rodajo de tierras que toma el rio" (LRL, fol. 149). El Libro de Repartimiento de Loja no alude en ningún momento a cultivos arbóreos existentes y por ello cabría pensar que nos encontramos ante tierras calmas. De hecho, la Crónica del Halconero de Juan II, al relatar el ataque a este lugar en |43|, alude a la tala de "muchos panes que ay abía", mientras que cuando se describe el ataque a Loja se habla de la tala de "panes e viñas e guertas" (CARRILLO, 1956, p. 98), lo cual coincide muy bien con las noticias que el mismo Libro de Repartimiento contiene en relación al espacio agrícola más próximo a la ciudad. Vinculado a la transformación del cereal está la referencia al molino de Taxara, entregado a la iglesia de Santa María (LRL, fol. XXXIV). En la actualidad, sobre el curso de la citada acequia, encontramos dos molinos, uno llamado de Tajadilla o Tajarilla y otro denominado Molino Calle. Por encima de la acequia se repartieron así mismo tierras de secano. Otro elemento destacado en la configuración de la alquería de Tájara es su situación en una zona de cruce de caminos, existiendo un vado por donde se cruzaba el río Genil. Se juntaban en esta zona los caminos reales de Granada a Loja y de Alhama a Montefrío (LRL, fol. $X X I X)$, mencionándose además un camino bajo de Tájara (LRL, fol. 86).

La prospección llevada a cabo en esta zona nos ha revelado la existencia de restos de muros de mampostería unida con mortero situados en la cara norte de la casería de Las Torres que tal vez correspondan a la fortaleza de época nazarí ubicada en esta zona y a la que alude el nombre de la casería. La cerámica hallada, no demasiado abundante, se corresponde con tipos que pueden datarse en época almohade y nazarí: ataifores vidriados, en melado o verde; cazuelas con vedrío melado; jarritas con decoración en manganeso; alcadafes vidriados; etc.

\section{LAS TRANSFORMACIONES EN EL POBLAMIENTO RURAL A RAÍZ DE LA INSTALACIÓN CASTELLANA}

La resistencia ofrecida por los habitantes musulmanes de la ciudad de Loja a la conquista castellana motivó que tras ésta fuesen expulsados, medida que probablemente afectó al conjunto de habitantes de su tierra. El proceso de instalación de la población castellana es bien conocido (MALPICA, 198I), por lo cual sólo lo trataremos brevemente. En primer lugar se delimitó el término lojeño, siguiendo -tal como vimos anteriormente- la división administrativa existente en la época nazarí, lo que permitió computar las tierras de cultivo disponibles para repartir. Sin embargo, como consecuencia de la guerra y de la epidemia de peste de 1487, el repartimiento de casas y tierras no comenzó de forma oficial hasta febrero de 1489 , finalizando en lo esencial en 1492. La repoblación constituyó un éxito, puesto que si los Reyes Católicos preveyeron la existencia de 500 pobladores, en diciembre de I49I había ya 506 vecinos, la mayor parte de los cuales procedían de los reinos de Córdoba y Jaén. Como es bien sabido, el reparto de tierras respondía al principio de desigualdad originaria $y$, en consecuencia, las diferencias entre los bienes entregados a peones, caballeros y escuderos de las Guardas fueron considerables, sin olvidar las importantes mercedes concedidas por los Reyes Católicos a aquellos personajes que habían destacado por sus servicios a la Corona. A la vez que se va desarrollando la repoblación va surgiendo un gobierno municipal más complejo, ya que en un principio el papel fundamental lo jugaba el alcaide de la fortaleza, Alvaro de Luna. En este gobierno entran las personas más influyentes de Loja, lo que dará lugar a la formación de una oligarquía urbana que va a controlar los mecanismos del poder político y económico de la ciudad.

La nueva organización del espacio rural establecida por los castellanos excluía la existencia de núcleos de población rural. Una relación castellana de fines del siglo XV indica que Loja está poblada con cristianos, mientras que Zagra, 
Tájara y Cexna estaban despobladas ${ }^{37}$, no existiendo ningún otro lugar poblado. Los únicos elementos del poblamiento rural eran los cortijos, que van a surgir en las medianas y grandes propiedades concedidas como mercedes a los personajes más destacados y dedicadas a una explotación extensiva de carácter agrícola y ganadero. De hecho esta asociación entre merced y cortijo se observa claramente en el caso de la merced de 300 fanegas de tierra concecida a Alonso de Toledo en el Campo de Abor que incluye "un zerrillo zerca de una fuente, fuera de sus tierras donde esta un edifiçio como pilar, çerca de unas ençinas en que haga una casa para el cortijo" (LRL, fol. 73). En este sentido la mayor parte de las torres de alquería fueron concedidas a los personajes que recibieron sus mercedes alrededor de ellas, para así aprovechar las construcciones existentes e integrarlas en las casas de los cortijos.

La iniciativa señorial será la única capaz de hacer surgir núcleos de población, como ocurre en el caso de Huétor y Salar, donde tenían grandes propiedades Alvaro de Luna y Fernando del Pulgar respectivamente, para lo cual recurrieron a pobladores mudéjares, probablemente habitantes de las antiguas alquerías existentes en ambos lugares, a los que ofrecieron una buenas condiciones para instalarse. El paso del señorío territorial al jurisdiccional fue más tardío.

La instalación castellana también va a suponer importantes modificaciones en la organización del espacio agrícola, produciéndose la expansión de los viñedos y los adehesamientos de los espacios ganaderos. Otro fenómeno a destacar es que la estructura de la propiedad de la tierra creada por la repoblación se deterioró rápidamente, produciéndose la concentración de la propiedad en manos de una minoría y la destrucción de la pequeña propiedad, lo que llevó a la necesidad de ampliar de nuevo el terrazgo agrícola, dando lugar al denominado "repartimiento de rozas" de 1506, que supuso un incremento notable de las tierras cerealistas de secano (MALPICA, 1981, p. 225).

\section{BIBLIOGRAFÍA}

Ajbar Maŷmūca, ed. y trad. E. Lafuente Alcántara, Madrid, 1867

ARJONA CASTRO, A. (1979):"El castillo de Turrush", Boletín de la Real Academia de Córdoba de Ciencias, Bellas Letras y Nobles Artes, XLIX. pp. 257-264.

ARJONA CASTRO, A. (1985): "Castillos de Córdoba: Carcabuey y Tiñosa", Boletín de la Real Academia de Córdoba de Ciencias, Bellas Letras y Nobles Artes, 109, pp. 89- 104.

BAEZA, HERNANDO DE ( 1868 ): "Las cosas que pasaron entre los reyes de Granada desde el tiempo de el rey Don Juan de Castilla, segundo de este nombre, hasta que los catholicos reyes ganaron el reyno de Granada", en LAFUENTE ALCÁNTARA, E.: Relaciones de algunos sucesos de los últimos tiempos del reino de Granada. Madrid.

BARRIOS AGUILERA, M. (1983): Historia de la Conquista de la Nobilísima Ciudad de Loja. Granada

BARRIOS AGUILERA, M. (1986): Moriscos en la tierra de Loja. El apeo de 157/-1574. Estudio y edición, Granada.

BARRIOS AGUILERA, M. (1988): Libro de los Repartimientos de Loja, I. Granada

BARRIOS AGUILERA, M. y MARTÍNEZ RUIZ, J. (1984): "Contribución a la toponimia andaluza: Loja y su tierra. Historia y lingüistica (según el 'Libro de Repartimiento')", Foro de las Ciencias y de las Letras, 7-8. pp. 43-44.

BAZZANA, A. y GUICHARD, P. (1978): "Les tours de défense de la Huerta de Valence au XIlle s.", Mélanges de la Casa de Velázquez, XIV. pp. I03-105

CARRASCO RUS ,J. et alii, (1986): El poblamiento antiguo de la tierra de Loja, Granada.

CARRIAZO, J.M. (197I): En la frontera de Granada. Sevilla

CARRILLO DE HUETE, P. (1956): Crónica del Halconero de Juan II, ed. J.M. Carriazo. Madrid.

CASTILLA BRAZALES, J. (1992): La crónica de Arib sobre al-Andalus, Granada.

CORRIENTE, F. (1988): El léxico árabe andalusí según P. de Alcalá. Madrid.

CRESSIER, P. (1984): "Le chateau et la division territoriales dans l'Alpujarre médiévale: du hișn a la țāaa, Melanges de la Casa de Velázquez, XX. pp. II5-144.

CRESSIER, P. (1988): "Eglises et chateaux dans l'Alpujarra a la fin du moyen age: l'implantation d'un pouvoir", en Sierra Nevada y su entorno. Granada.

37 Archivo General de Simancas, Cámara de Castilla, Libro de Cédulas 254. 
DÍAZ GARCÍA, A. y BARRIOS AGUILERA, M. (1991): De toponimia granadina, Granada.

ESLAVA GALÁN, J. ( 1984): "Materiales y técnicas de construcción en la fortificación bajomedieval", Cuadernos de Estudios Medievales, XII-XIII. pp. 27I-278.

FERNÁNDEZ CAPEL-BAÑOS, B. (1971.): "Un fragmento del 'Kitab al-Ŷ́u'rāfiyya' de al-Zuhrï", Cuadernos de Historia del Islam, III. I09-124.

FERNÁNDEZ DE CÓRDOBA, F. Abad de Rute,(1958): "Historia y descripción de la antigüedad y descendencia de la Casa de Córdoba", Boletín de la Real Academia de Córdoba de Ciencias, Bellas Letras y Nobles Artes, 77. pp. 209-256.

FERNÁNDEZ DE CÓRDOBA, F., Abad de Rute (1961): "Historia y descripción de la antigüedad y descendencia de la Casa de Córdoba", Boletín de la Real Academia de Córdoba de Ciencias, Bellas Letras y Nobles Artes, 81. pp. 293-324.

FIERRO, M. I. (1990): "Familias en el Ta'rij iftitāh alAndalus de Ibn al-Qūțiyya", Estudios onomástico-biográficos de al-Andalus, IV, Granada. pp. 4I-70.

GAMIR SANDOVAL, A. (1956): "Reliquias de las defensas fronterizas de Granada y Castilla en los siglos XIV y XV", Miscelánea de Estudios Arabes y Hebraicos, 5. pp. 43-72.

GARRIDO ATIENZA, M. (1992): Las capitulaciones para la entrega de Granada, edición facsímil, Granada.

GENER BASALLOTE, J.M. et alii, (1992): Loja durante el dominio romano. Metodología, técnicas e interpretación del yacimiento de Plines, Granada.

IBN HAYYĀN: "Al-Muqtabis de Ibn Hayyān", trad. J.E. Guraieb, Cuadernos de Historia de Éspaña, vols. XIII (1950) a XXXI-XXXII (1960).

IBN AL-JATTīB (1976): al-Iḥāța fi ajbār Garnāța, ed. 'Abd Allāh Inān, vol. III. El Cairo.

JIMÉNEZ MATA, M.C. (1990): La Granada Islámica, Granada.

LADERO QUESADA, M.A. (1988): Granada después de la conquista. Repobladores y mudéjares, Granada.

LADERO QUESADA, M.A. (1989): Granada. Historia de un país islámico (I232-|57|), Madrid.

LAFUENTE ALCANTARA, E. (1868): Relaciones de algunos sucesos de los últimos tiempos del reino de Granada. Madrid.

LÓPEZ, T. (1990): Diccionario geográfico de Andalucía: Granada, Sevilla.

MADOZ, P. (1987): Diccionario geográfico-estadístico-histórico de Andalucía. Granada, Salamanca.
MALPICA CUELLO, A. (1981): El Concejo de Loja (1486-1508). Granada.

MALPICA CUELLO, A. (1987): "El castillo de Zagra y el alfoz de Loja a fines de la Edad Media", Homenaje al Profesor Juan Torres Fontes, II, Murcia .pp. 959-973

MALPICA CUELLO, A. (199|): "Fiscalidad y comercio de la sal en el reino de Granada en la Edad Media", Das salz in der rechts- und handelsgeschichte, Berenkamp. pp. 65-94.

MALPICA CUELLO, A. y QUESADA QUESADA, T.(1993): Colección de documentos reales del Archivo Municipal de Loja (1488-15/5), Granada.

MUNIS, H. (1957): "La división político-administrativa en la España musulmana", Revista del Instituto de Estudios Islámicos en Madrid, V. pp. 79- 135.

NIETO CUMPLIDO, M. (1979): Corpus medieavale cordubense, I, Córdoba.

NIETO CUMPLIDO, M. (1980): Corpus medieavale cordubense, II. Córdoba.

PELLICER, M. (1962): "Actividades de la delegación de zona de la provincia de Granada durante los años 19571962", Noticiario Arqueológico Hispánico, VI. pp. 304-305.

PEZZI, E. (1989-1990): "Algunos topónimos del campo de Almería (el Alquián, el Mamí, el Juaida, el Bobar, Mazarulleque, Pujaire)", Miscelánea de Estudios Árabes y Hebráicos, 38. pp. 255-268.

ROMERO MARTÍN, M. y ROSA BERBEL, J. (1986): "Informe sobre prospección arqueológica superficial: Zagra (Granada)", Anuario Arqueológico de Andalucía. p. $126-128$.

SÁNCHEZ RODULFO, R. (1987): El Concejo de Loja. Libro de Actas Capitulares III (1512-1517), Memoria de Licenciatura inédita, Granada.

SECO DE LUCENA, L. (1910): Plano de Granada árabe. Granada

SECO DE LUCENA PAREDES, L. (1964): "Toponimia árabe de la vega y los montes de Granada", Al-Andalus, XXIX. p. 3। I-327.

SECO DE LUCENA PAREDES, L. (1974): Topónimos árabes identificados, Granada.

SECO DE LUCENA PAREDES, L. (1978): Muhammad IX, sultán de Granada, Granada.

VALLVÉ BERMEJO, J. (1986): La división territorial de la España musulmana, Madrid.

VÁZQUEZ RUIZ, J. (1959-1960.): "Una versión árabe occidental de la leyenda de los Siete Durmientes de Efeso", Revista del Instituto de Estudios Islámicos en Madrid, VII-VIII. p. 4I - I 8. 


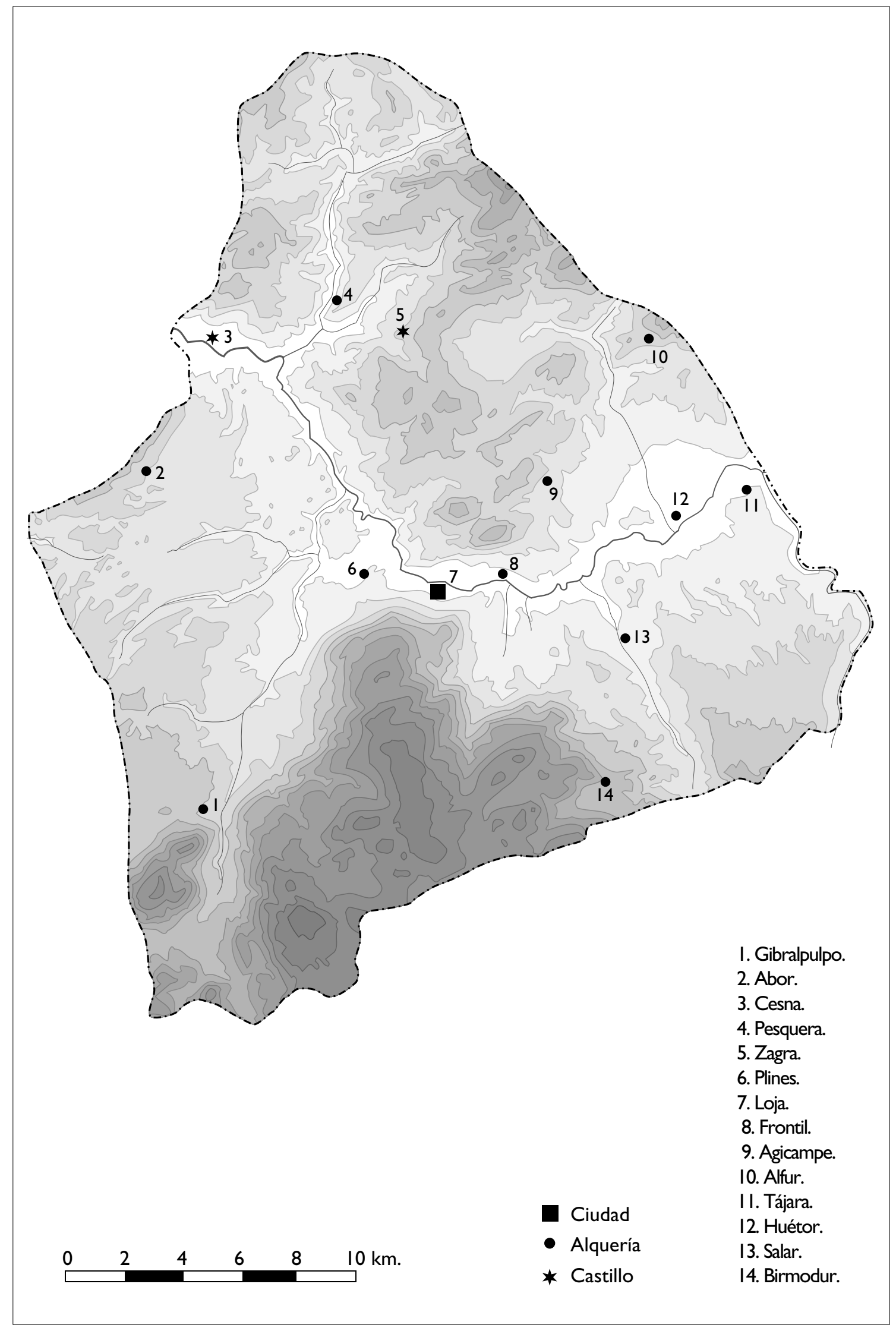

Mapa. El poblamiento de la tierra de Loja en la época nazarí 